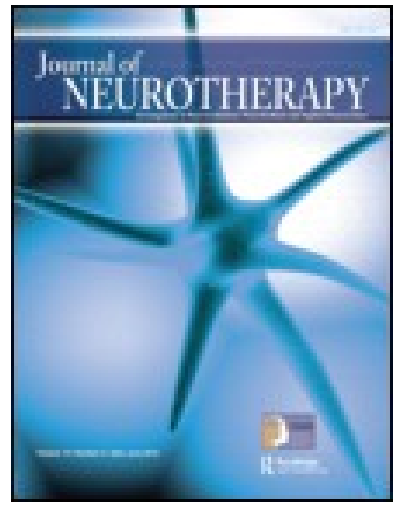

J ournal of Neurotherapy: Investigations in Neuromodulation, Neurofeedback and Applied Neuroscience

\title{
Effects of Neurofeedback Training on Attention in Children with Intellectual Disability
}

Changhee Hong ${ }^{a} \&$ Inkyoung Lee ${ }^{b}$

a Department of Psychology , Pusan National University, Busan, Korea

b Sodap Elementary School , Changwon, Korea

Published online: 29 May 2012.

To cite this article: Changhee Hong \& Inkyoung Lee (2012) Effects of Neurofeedback Training on Attention in Children with Intellectual Disability, J ournal of Neurotherapy: Investigations in Neuromodulation, Neurofeedback and Applied Neuroscience, 16:2, 110-122, DOI: $\underline{10.1080 / 10874208.2012 .677666}$

To link to this article: http:// dx.doi.org/ 10.1080/ 10874208.2012.677666

PLEASE SCROLL DOWN FOR ARTICLE

(C) International Society for Neurofeedback and Research (ISNR), all rights reserved. This article (the "Article") may be accessed online from ISNR at no charge. The Article may be viewed online, stored in electronic or physical form, or archived for research, teaching, and private study purposes. The Article may be archived in public libraries or university libraries at the direction of said public library or university library. Any other reproduction of the Article for redistribution, sale, resale, loan, sublicensing, systematic supply, or other distribution, including both physical and electronic reproduction for such purposes, is expressly forbidden. Preparing or reproducing derivative works of this article is expressly forbidden. ISNR makes no representation or warranty as to the accuracy or completeness of any content in the Article. From 1995 to 2013 the J ournal of Neurotherapy was the official publication of ISNR (www. Isnr. org); on April 27, 2016 ISNR acquired the journal from Taylor \& Francis Group, LLC. In 2014, ISNR established its official open-access journal NeuroRegulation (ISSN: 2373-0587; www. neuroregulation. org).

THIS OPEN-ACCESS CONTENT MADE POSSIBLE BY THESE GENEROUS SPONSORS

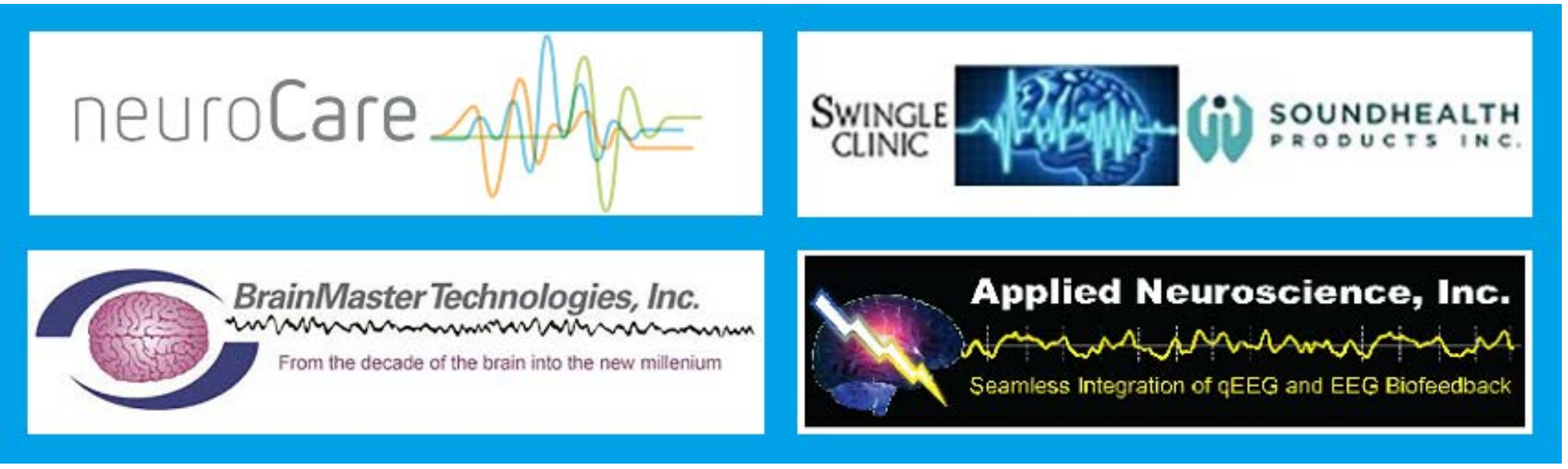




\title{
EFFECTS OF NEUROFEEDBACK TRAINING ON ATTENTION IN CHILDREN WITH INTELLECTUAL DISABILITY
}

\author{
Changhee Hong ${ }^{1}$, Inkyoung Lee ${ }^{2}$ \\ ${ }^{1}$ Department of Psychology, Pusan National University, Busan, Korea \\ ${ }^{2}$ Sodap Elementary School, Changwon, Korea
}

\begin{abstract}
This study investigated effects of neurofeedback (NFB) training on attention in children with intellectual disability (ID). Twenty-one children with ID were assigned to an NFB training group $(n=7)$, to a visual perception (VP) training group $(n=7)$, or to a no-treatment group $(n=7)$. Two groups received 36 sessions of NFB or VP training, respectively, over 12 weeks. Children's Color Trails Test-2, Stroop Color and Word Test, and Digit Span were administered to all participants before and after training. The follow-up study was conducted with both the NFB and VP groups in the same way after 3 months. The EEGs of the NFB group also were measured. The NFB group showed significantly improved scores on the all tests compared to the 2 control groups. The brainwaves of the frontal lobes of the NFB group declined significantly in theta wave amplitude and theta-to-beta ratio. The NFB results were maintained in the follow-up study. Beta/SMR uptraining seemed to be an effective way to enhance attention in children with ID.
\end{abstract}

\section{INTRODUCTION}

Intellectual disability (ID) is a disability characterized by significant limitations both in intellectual functioning and in adaptive behavior, which covers a range of everyday social and practical skills (American Association of Intellectual and Developmental Disabilities, 2010).

Attention is a fundamental ability in information processing, which is essential to acquire knowledge, information, and social skills during school years (Rizzo \& Buckwalter, 1997). Inattentive behaviors can cause school and work underachievement, cause low selfesteem, and negatively influence interpersonal relationships with peers (Thorell \& Rydell, 2008). For example, inattentive children with ID get distracted easily by external stimuli, have difficulties focusing, and have trouble coping with stimuli given to them simultaneously. Difficulties in attention can result in academic failure and maladaptive behaviors in school that will have negative effects on later social life (Deci, 2004; Kirk \& Gallagher, 1983; Switzky, 2001). Therefore, improving attentional ability is a priority for children with ID.

Researchers have studied various methods to improve attentional ability in children with ID. Research has mostly focused on factors within educational environments causing attention deficits and on finding educational materials that can improve attentional ability. Many researchers have developed methods for children with ID to improve their learning and adaptive behaviors. Methods include behavior modification, exercise therapy, visual perception (VP) training, and sensory integrative therapy (Allinder, 2000; Fox \& Oross, 1992; Tomporowski \& Ellis, 1984; Uyanik, Bumin, Kayihan, \& Bumin, 2003). One example of this is a VP training program intended to improve VP and attentional ability through training perceptual discrimination between figure and ground. A study found that VP processing

Received 4 February 2012; accepted 5 March 2012.

Address correspondence to Changhee Hong, PhD, Department of Psychology, Pusan National University, 30 Jangjeon-dong, Geumjeong-gu, Busan 609-735, Korea. E-mail: hch2144@yahoo.co.kr 
involves the frontal lobes in individuals with IDs (Muñoz-Ruata, Caro-Martínez, Pérez, \& Borja, 2010). Consequently, VP training is expected to enhance frontal lobe function. Results of the VP training program showed mild effects on attention improvement and learning preparedness to the specific tasks but also had limitations in maintaining effects and generalization of tasks (Rezaiyan, Mohammadi \& Fallah, 2007; Stogdill, 1938).

Recently, neuropsychological methods are attracting researchers' attention. The most wellknown method is neurofeedback (NFB). In NFB, principles of reinforcement are applied to improve attention by activating or reducing brainwaves. NFB activates brainwaves related to attention, reduces brainwaves not related to it, and subsequently develops brain function widely (Hoza \& Pelham, 1993). NFB is noninvasive with few adverse effects if performed correctly and increases self-regulation skills (Egner \& Gruzelier, 2001).

Most studies using NFB related to attentional improvement mainly focused on children with attention deficit hyperactivity disorder (ADHD) or learning disorder (LD; Gracenin \& Cook, 1997; Hernandez et al., 2002; J. F. Lubar, Swartwood, Swartwood, \& Timmermann, 1995). Brain imaging studies of children with ADHD or LD showed meaningful relations between the behavioral symptoms of these disorders and neurophysiological factors (Castellanos, 1997; Fernandez et al., 2007; Filipek, 1999). Moreover, recent studies of the relationship between electroencephalography (EEG) and ADHD have supported the NFB training protocols (Arns, Gunkelman, Breteler, \& Spronk, 2008; Monastra, Lubar, \& Linden, 2001). If NFB training is effective for ADHD or LD children having neurological limitations, this kind of neurological method could also be applied to children with ID (Luria, 1973).

Attention is dependent on interactions among brain structures (Mesulam, 1981; Ponser \& Peterson, 1990). It is known that the specific regions related to inattention are the frontal lobe and reticular activation system (RAS) for children with ID. The frontal lobe is closely related to attention, executive function, and working memory (Arnsten \& Li, 2005). Other studies have found that patients with damage to frontal lobes showed difficulties in attention tasks (Duncan \& Owen, 2000; Welsh, Pennington, \& Grosser, 1991). The RAS involves brain structures, such as locus coeruleus and basal forebrain, and plays an important role in attentional ability in children with ID by controlling arousal levels. Accordingly, if we can have a direct effect on neurological functions such as activation of frontal lobe and arousal level of the RAS through NFB training, we should be able to improve brain functions related with attention and arousal of children with ID.

\section{Attentional Processing}

Attention is involved in the informationprocessing system that helps the brain to work effectively (Lavie, 2005). Attention is a goal-directed and active process that helps us focus on a specific task and target. Consequently, attention can be defined as a process through which we can obtain useful information for task completion from ongoing events, and then infer anticipated results (Corbetta \& Shulman, 2002; Eysenck \& Keane, 2005). Attention has three primary functions: (a) alerting refers to activating a preparative state to receive external information, (b) filtering refers to the ability with which we can discern and select specific information from among several stimuli, and (c) allocating allows us to distribute our attention among more than two stimuli (Posner \& Peterson, 1990).

Neuroanatomical studies on attentional mechanisms reveal associated neuroanatomical structures by measuring neurological activities, brainwaves, or changes in cerebral blood flow that appear while attention tasks are performed. Posner (1980) proposed three activity networks directly involved in selective attention. First, an orienting attentional network consists of engaging, disengaging, and shifting processes. Once we pay attention to a target, we engage in the target. If we want to give attention to another one, we disengage our attention from the old target, and then we can shift our attention to the new target. The thalamus, superior colliculus of the midbrain, and 
the parietal lobe activate in the engaging, shifting, and disengaging processes, respectively (LaBerge, 1995; Posner \& Raichle, 1994). The executive control attention network activates when we sense a target object and then process ongoing information intentionally. The anterior cingulate, left frontal cortex, and basal ganglia are involved in this process (Jackson, Marroccos, \& Posner, 1994). Last, the vigilance network maintains a proper psychological state through which we can give attention to external stimuli. During this process, increased blood flow in the parietal and frontal lobes of the right hemisphere are observed (Posner \& Raichle, 1994).

Neuroanatomical research on attention shows that the frontal lobe is involved in both the executive control attention and vigilance networks. Consequently, it could be hypothesized that we can stabilize arousal levels and enhance executive function of children with ID by activating the frontal lobe.

\section{Training Mode and Clinical Application of NFB}

Although NFB could be a powerful method in improving attention and related cognitive functions, there has been little systematic study to date for children with ID. In the study reported here, the effects of NFB training for children with ID were investigated. Unlike a traditional method focused on behavioral reinforcement, we expect NFB training focused on neurological reinforcement to bring more direct and fundamental improvements in attentional ability.

Eyes-open beta/sensorimotor response (SMR) amplitude uptraining is known to be helpful for people with ADHD, LD, epilepsy, and sleep disorder. It has been reported that beta training $(15-18 \mathrm{~Hz})$ can normalize left brain function, and SMR training $(12-15 \mathrm{~Hz})$ can stabilize right brain function in these disorders (Othmer, Othmer, \& Marks, 1991). Beta waves $(14-30 \mathrm{~Hz})$ faster than SMR are related to focusing attentional ability. Beta and SMR waves may be set up as reward frequency bandwidths during NFB training. When the amplitude of the beta/SMR bandwidth exceeds that of $4-7 \mathrm{~Hz}$ theta beyond a predetermined threshold, reinforcement is provided (Rossiter, 2002).
Considering the cognitive limitations in ID, research related to improving attentional ability for children with ID would be not only meaningful but also important. More systematic and organized studies are needed. Despite potential effects of NFB training, surprisingly little research has been conducted for children with ID so far (Bachers, 2004; Fleischman \& Othmer, 2005). Bachers (2004) conducted NFB training for one child with ID and cerebral palsy and showed brain changes on computed tomography. Fleischman and Othmer (2005) reported increased IQ score of an identical twin with mild ID after NFB training. Both studies were case studies targeted at only one or two children with ID.

In this study, we investigated NFB training effects for a group of children with ID, comparing training effects of a NFB group to those of both a no-treatment control group and a VP training group. Besides investigating differences in effects on attention tasks, we also tried to identify fundamental differences produced in brainwave activity. Three months following completion of training, a follow-up study was performed in order to ascertain the long-term effects of the NFB.

\section{METHOD}

\section{Participants}

Participants were 21 elementary school students (Grade 3-6) with mild ID. They were randomly assigned to a NFB training group $(n=7)$, a VP training group $(n=7)$, or a control group $(n=7)$. They were receiving special education in an independent classroom. Thirty-six sessions of NFB and VP training were conducted in the two training groups, respectively, three sessions a week, 30 min per session during 12 weeks. Two special education teachers conducted the NFB and VP training, respectively. Informed consent was obtained from the parents of all participants.

Table 1 shows mean and standard deviation of age, grade, and intelligence for each group. The intelligence index was determined using the Korean Version of the Wechsler 
TABLE 1. Mean and Standard Deviation of Age, Grade, and Intelligence for Each Group

\begin{tabular}{lcll}
\hline Group & Age & Grade & Intelligence \\
\hline NFB $(n=7)$ & $10.57(1.25)$ & $4.85(1.16)$ & $67.4(4.3)$ \\
VP $(n=7)$ & $10.43(1.13)$ & $4.57(1.27)$ & $65.2(2.7)$ \\
Control $(n=7)$ & $9.86(.90)$ & $4.42(1.13)$ & $66.6(4.7)$ \\
Total $(\mathrm{N}=21)$ & $10.19(1.23)$ & $4.57(1.28)$ & $66.8(3.6)$ \\
\hline
\end{tabular}

Note. The intelligence index was determined by the Korean Version of the Wechsler Intelligence Scale for Children-Third Edition. $\mathrm{NFB}=$ neurofeedback; $\mathrm{VP}=$ visual perception.

Intelligence Scale for Children-Third Edition (WISC-III; Kwak, Park, \& Park, 2001). There were no significant pretreatment differences in age, grade, and intelligence among groups.

\section{NFB Training}

Previous research has reported that a NFB protocol providing positive feedback in response to increasing beta $(14-30 \mathrm{~Hz})$ activity was effective for improving attentional ability in children with ADHD or LD (J. F. Lubar, 1991; J. O. Lubar \& Lubar, 1984; Othmer et al., 1991; Shouse \& Lubar, 1979; Tansey, 1991). Another protocol that inhibited theta $(4-7 \mathrm{~Hz})$ and increased low beta $(15-18 \mathrm{~Hz})$ activity was conducted for children with ADHD or LD. Results showed that subjects showed a significant improvement on each subscale of the WISC-R (J. F. Lubar, 1995). Another different protocol that inhibited theta and activated beta was used for children with ADHD, and resulted in increased scores on the Kaufman Brief Intelligence Test and on attentional ability (Linden, Habib, \& Radojevic, 1996). Theta amplitude was predominant over SMR for children with LD, especially when they were inattentive (J. F. Lubar, 1985); SMR training could stimulate the brain state leading to enhanced attentional ability (Shouse \& Lubar, 1979). In conclusion, the training mode that inhibits theta and reinforces beta/SMR activity should be the most effective for improving attentional ability.

In this study, the NFB program system, "Neuroharmony M" (Braintech Corp., Korea), designed by the Korea Research Institute of Jungshin Science, was used. This program not only includes NFB training but also displays measurements of brainwaves during training.
The correlation coefficient with the Grass System (USA) for alpha, beta, and theta values was .92 ( $p<.001$; Kim, 2000). Brainwaves were measured through three channels (Fp1, $\mathrm{Fpz}, \mathrm{Fp} 2$ ) attached to a headband with a reference electrode on the left earlobe. EEGs measured from the frontal lobe were used for NFB. Participants could adjust their brainwaves along with the outputs of the game. Reinforcement such as a picture of a bending a spoon was given on screen if the subject's brainwaves exceeded the threshold of the selected frequency bandwidths. In this study, attention and concentration training were used as training modes.

Four programs were used in this study. A painting program (summarized next) was used for selecting the training mode. If a participant showed weak performance on the attention mode compared to the concentration mode, the attention mode was selected as a training mode for 3 weeks, and vice versa. After 3 weeks, brainwaves were reanalyzed, and a training mode was reselected. The other three programs such as making a cup, bending a spoon, and shooting an arrow were used for training. Considering students' interests and participation, the training program was performed only for 3 weeks. When participants gained high scores in the training mode, a bonus game such as car racing or memorizing planet names were provided.

Painting. A picture is painted depending on brainwave activity level. If the brainwave activity meets threshold criteria for the targeted frequency band, black and white images on the screen turn into colorful images.

Making a cup. A cup-making activity is completed as targeted brainwave activity meets threshold criteria. If the level of brainwave activity meets criterion, a beep sounds. Participants can recognize their brain activity level through the feedback like a beep sound or the screen image. The number of cups made also is visually scored.

Shooting an arrow. When brainwaves satisfy the training conditions, a beep sounds. Clicking a mouse button in accordance with sound signal increases the possibility of hitting 
the mark. The training is finished when 15 pieces of arrows are used for $2 \mathrm{~min}$. The score means the extent of achievement.

Bending a spoon. A spoon is bent, and a beep sounds when brainwaves reach a proper level. If the brainwaves fall below threshold, the beep sound doesn't occur and a bent spoon goes back into an unfolded, straight position. The scores depend on how many spoons are bent completely.

\section{VP Training}

VP training is designed to improve VP ability. In this study, the adapted version (Yeo, 1987) of a VP training program (Frostig \& Horne, 1964) was used. As shown in Table 2, the program consists of five parts: visual-motor integration, figure-ground, position in space, spatial relations, and form constancy. In this study, 30 tasks for each part were selected and reconstructed according to the children's developmental and intellectual level.

\section{Measures}

Children's Color Trails Test (CCTT). CCTT is a test that measures visuomotor, attentional, and execution ability for children ages 8 to 15 (Llorente, Williams, Statz, \& D'Elia, 2003). CCTT consists of two subtests. CCTT-1 measures continuous attentional ability, and CCTT-2 measures distributed attention and inhibition/disinhibition ability. In this study, only CCTT-2 of the Korean version (Shin \& Park, 2007) was used. The test-retest reliability for this instrument is .75. Scores for the CCTT-2 shown at tables and figures to follow are standard scores.

Stroop Color and Word Test (SCWT). The Stroop test designed by Charles Golden in 1974 measures children's attention. The test consists of a word test, a color test, and a word-color test and mostly measures inhibition function. In this study, only the word-color test of the Korean version (Shin \& Goo, 2007) for children age 5 to 14 was used. The test-retest reliability is .72. Scores of SCWT shown in the following tables and figures are standard scores.

Digit Span. We used a modification of the Digit Span test of the WISC-R (Wechsler, 1974). Our modification included a different arrangement of numbers than in the original test. The test consists of seven items that have three series of different numbers. The first item is composed of one digit, the second of two digits, and up to seven digits in the order. If successful on any item, participants get 1 point. The total number of points is 21. Scores of Digit Span shown in tables and figures are raw scores.

\section{Procedure}

NFB procedure. The NFB training program for children with ID was performed in the special classroom in an elementary school, Kyungnam province. One week before training, participants were given instructions for the training. When students came into the classroom, they sat down and took some relaxation time in a comfortable condition for $5 \mathrm{~min}$. First, we attached the electrode headband with the Fpz electrode on the center, Fp1 on the

TABLE 2. Number of Items and Contents of Training in VP Training Program

\begin{tabular}{|c|c|c|c|c|c|c|}
\hline \multirow[b]{2}{*}{ Part } & \multicolumn{3}{|c|}{$\mathrm{N}$ of items at each level by Frostig Program } & \multirow[b]{2}{*}{ Total } & \multirow[b]{2}{*}{ Training contents } & \multirow{2}{*}{$\begin{array}{l}\mathrm{N} \text { of items } \\
\text { selected }\end{array}$} \\
\hline & Beginner & Intermediate & Advanced & & & \\
\hline VM & 44 & 22 & 16 & 82 & Drawing along a circle & 2 \\
\hline FG & 8 & 35 & 20 & 63 & Painting & 2 \\
\hline FC & 22 & 26 & 20 & 68 & Crossing paintings & 9 \\
\hline PS & 6 & 12 & 19 & 37 & Perception of figure & 8 \\
\hline SR & 0 & 17 & 53 & 70 & Rotating figure with upside down & 9 \\
\hline Total & 80 & 112 & 128 & & & 30 \\
\hline
\end{tabular}

Note. $\mathrm{VP}=$ visual perception; $\mathrm{VM}=$ visual-motor integration; $\mathrm{FG}=$ figure-ground; $\mathrm{PS}=$ position in space $\mathrm{SR}=$ spatial relations; $\mathrm{FC}=$ form constancy. 
left, and $\mathrm{Fp} 2$ on the right of forehead, with a reference electrode on the left earlobe. We checked overall instrument and electrode attachment conditions for participants and gave them directions. Directions were as follows:

The purpose of this training is to learn the ability to be able to control brainwaves while simultaneously playing games. Sit down comfortably in the chair and enjoy playing games using your brain. During training you should not touch the headband on your head. Please keep silent and pay attention to playing games with a relaxed mind.

Additional explanations or coaching were given to participants during training. When there was a rewarding event, the instructor would reward the participant with explanations of his or her brainwave condition. We expected those explanations to help participants to understand the relationship between their brain activity and changes shown on their monitor.

Assessment procedure. The CCTT-2, SCWT, and Digit Span tests were administered before and after completion of the NFB and VP training programs, and a follow-up study was conducted 3 months after the training completion.

\section{Data Analysis}

An analysis of variance was performed to test the training effects. The independent variables were time (before and after training) and group (NFB, VP, and control group). Dependent variables were scores on the CCTT-2, Stroop, and Digit Span. If there were significant differences in pre-treatment scores among the groups, an analysis of covariance was performed using pretest scores as a covariant. Next, we completed a $t$ test on changes in amplitude levels for the selected frequency bands (theta, alpha, beta), as well as beta/theta ratios, to identify brainwave changes in the left and right frontal lobes for the NFB group participants. The follow-up study was conducted to determine the consistency of training effects after 3 months.

\section{RESULTS}

\section{Attention Training Effects}

CCTT-2. Table 3 shows the mean and standard deviation of CCTT-2 scores before and after training. After training, the NFB group showed significantly higher scores compared to the two other groups, $F(2,18)=3.30, p<.05$. A significant increase was observed in CCTT-2 for the NFB training group, but there were no differences for VP training and control groups before and after training. Figure 1 shows that the NFB training group performed better on the CCTT-2 compared to the VP training group and the no-treatment control group.

SCWT. Table 4 shows the mean and standard deviation of SCWT scores before and after training for each group. The NFB group showed 2 to 4 times higher scores than the other two groups. The interaction effects between before and after scores for the NFB group were $F(2$, $18)=3.35, p<.05$. There was a significant increase in pre-post treatment scores for the NFB group, $t(6)=-2.74, p<.05$, but no differences for the VP and control groups. Figure 2 shows that the children in the NFB training group improved significantly on this measure compared to both the VP and control groups.

Digit Span. Table 5 shows the mean and standard deviation scores on the Digit Span test for each group before and after training. All three groups showed increased scores, but with greater differences for the NFB group. A significant interaction effect within each group before and after training was observed, $F(2$, $18)=6.13, p<.05$. The NFB group showed a significant increase from pre- to posttesting,

TABLE 3. Mean and Standard Deviation of CCTT-2 Scores Before and After Training

\begin{tabular}{|c|c|c|c|c|}
\hline & Group & $\begin{array}{l}\text { Before } \\
M(S D)\end{array}$ & $\begin{array}{l}\text { After } \\
M(S D)\end{array}$ & Paired $t$ \\
\hline ССТТ-2 & $\begin{array}{l}\text { NFB }(n=7) \\
\text { VP }(n=7) \\
\text { Control } \\
(n=7)\end{array}$ & $\begin{array}{l}35.43(13.46) \\
33.57(6.32) \\
31.57(9.96)\end{array}$ & $\begin{array}{l}41.43(13.72) \\
35.43(8.36) \\
32.14(9.65)\end{array}$ & $\begin{array}{l}3.74^{* *} \\
0.83 \\
1.33\end{array}$ \\
\hline $\begin{array}{c}\text { Note. } \\
\text { neurofee } \\
{ }^{* *} p<.\end{array}$ & CСТT $-2=$ & $\begin{array}{l}\text { ildren's Colc } \\
\text { ual perceptio } \\
\text { test. }\end{array}$ & Trails Test; & $\mathrm{NFB}=$ \\
\hline
\end{tabular}




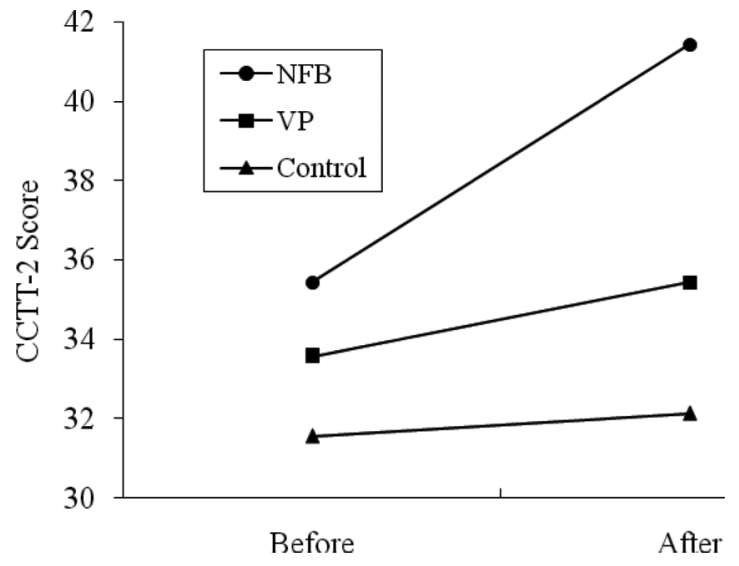

FIGURE 1. Changes of Children's Color Trails Test (CCTT-2) score before and after training. $\mathrm{NFB}=$ neurofeedback; $\mathrm{VP}=$ visual perception.

TABLE 4. Mean and Standard Deviation of SCWT Scores Before and After Training

\begin{tabular}{|c|c|c|c|c|}
\hline & Group & $\begin{array}{l}\text { Before } \\
M(S D)\end{array}$ & $\begin{array}{l}\text { After } \\
M(S D)\end{array}$ & $\begin{array}{l}\text { Within } \\
\text { subjects } \\
\text { (paired } t \text { ) }\end{array}$ \\
\hline \multirow[t]{3}{*}{ SCWT } & NFB $(n=7)$ & $27.00(6.29)$ & $31.29(6.60)$ & $2.74^{* *}$ \\
\hline & $\mathrm{VP}(\mathrm{n}=7)$ & $29.00(5.09)$ & $31.13(7.47)$ & 0.37 \\
\hline & Control $(n=7)$ & $28.43(4.69)$ & $29.14(4.91)$ & 1.36 \\
\hline
\end{tabular}

Note. $\mathrm{NFB}=$ neurofeedback; $\mathrm{VP}=$ visual perception; $\mathrm{SCWT}=$ Stroop Color and Word Test.

${ }^{*} p<.05$, one-tailed test.

$t(6)=-3.65, p<.01$, but no differences were found for both the VP and control group, as shown in Figure 3.

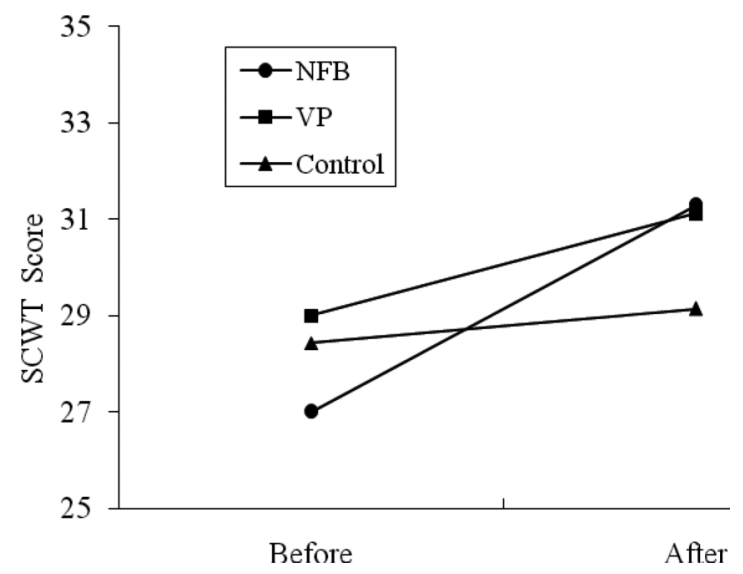

FIGURE 2. Changes of Stroop Color and Word Test (SCWT) score before and after training. $\mathrm{NFB}=$ neurofeedback; $\mathrm{VP}=$ visual perception.
TABLE 5. Mean and Standard Deviation of Digit Span Before and After Training

\begin{tabular}{lllll}
\hline & & Before & After & \\
& Group & $M(S D)$ & $M(S D)$ & Paired $t$ \\
\hline Digit & NFB $(\mathrm{n}=7)$ & $8.29(3.40)$ & $12.19(3.25)$ & $3.65^{* *}$ \\
Span & VP $(\mathrm{n}=7)$ & $8.00(3.41)$ & $8.86(7.47)$ & 1.12 \\
& Control $(\mathrm{n}=7)$ & $7.86(2.34)$ & $8.71(2.63)$ & 3.28 \\
\hline
\end{tabular}

Note. Digit Span test consists of seven items and each item includes three problems. The Digit Span test is a modified form based on Wechsler Intelligence Scale for Children-Revised. $\mathrm{NFB}=$ neurofeedback; $\mathrm{VP}=$ visual perception

${ }^{* *} p<.01$, one-tailed test.

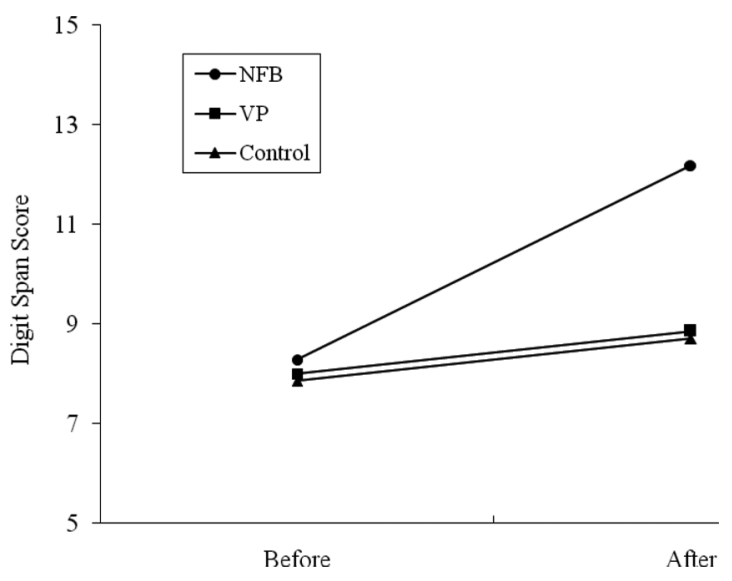

FIGURE 3. Changes of Digit Span before and after training. $\mathrm{NFB}=$ neurofeedback; $\mathrm{VP}=$ visual perception.

\section{Brainwave Changes}

Because the NFB group showed considerable improvement on the measures of attentional ability, their frontal lobe brainwave changes were examined to identify direct effects of the NFB training on their brainwaves. Amplitude

TABLE 6. Mean and Standard Deviation of Frequency Values for Fp1 Before and After Training in NFB Group $(N=7)$

\begin{tabular}{lllr}
\hline & Before & After & \\
Brain wave & $M(S D)$ & $M(S D)$ & Paired $t$ \\
\hline Theta & $10.86(4.43)$ & $8.47(3.65)$ & $-2.24^{*}$ \\
Alpha & $4.93(2.39)$ & $5.38(2.27)$ & 0.56 \\
Beta & $2.68(1.02)$ & $2.28(0.95)$ & 0.77 \\
Theta: Beta & $3.77(0.86)$ & $3.06-1.09$ & $-1.44^{*}$ \\
\hline
\end{tabular}

Note. Scores for each frequency include mean and standard deviation scores of power value ranging $4-20 \mathrm{~Hz}$ per second, which were measured for $120 \mathrm{~s}$. Beta ranges from SMR wave $(12 \sim 15 \mathrm{~Hz})$ to low beta wave $(16 \sim 20 \mathrm{~Hz})$. NFB = neurofeedback.

${ }^{*} p<.05$, one-tailed test. 
TABLE 7. Mean and Standard Deviation of Frequency Values for Fp2 Before and After Training in NFB Group $(N=7)$

\begin{tabular}{lccr}
\hline & \multicolumn{1}{l}{ Before } & \multicolumn{2}{l}{ After } \\
Brain Wave & $M(S D)$ & $M(S D)$ & Paired $t$ \\
\hline Theta $(\mathrm{n}=7)$ & $1.63(0.56)$ & $1.39(0.37)$ & -1.72 \\
Alpha $(\mathrm{n}=7)$ & $0.35(0.08)$ & $0.35(0.09)$ & 0.93 \\
Beta $(\mathrm{n}=7)$ & $0.04(0.02)$ & $0.05(0.03)$ & 1.44 \\
Theta: Beta $(\mathrm{n}=7)$ & $49.48(23.04)$ & $41.56(20.65)$ & $-2.40^{*}$ \\
\hline
\end{tabular}

Note. Scores for each frequency include mean scores of power value ranging $4-20 \mathrm{~Hz}$ per second, which were measured for $120 \mathrm{~s}$. Beta ranges from SMR wave $(12 \sim 15 \mathrm{~Hz})$ to low beta wave $(16 \sim 20 \mathrm{~Hz}) . \mathrm{NFB}=$ neurofeedback.

${ }^{*} p<.05$, one-tailed test.

levels for each frequency (theta, alpha, and beta) and changes in theta/beta ratio were measured in the txt file format for $120 \mathrm{~s}$ and transformed to a fast Fourier transform file. Power values per second ranging $4-20 \mathrm{~Hz}$ were recorded. Mean scores for each theta, alpha, and beta range were calculated based on power values. Last, changes in brainwave amplitudes before and after training were compared in the left (Fp1) and right frontal lobe (Fp2). In the study, beta/SMR uptraining was designed to increase beta $(16-20 \mathrm{~Hz})$ and SMR $(12-15 \mathrm{~Hz})$ and to decrease theta (4$7 \mathrm{~Hz})$ at $\mathrm{Fp} 1$ and $\mathrm{Fp} 2$ of frontal lobes. So decreases in theta/beta ratio owing to increases in beta and SMR activity and decreases in theta activity were anticipated. Tables 6 and 7 show brainwave changes at Fp1 and Fp2, respectively. As expected, the activity level of theta at Fp1 declined significantly, $t(6)=-2.24$, $p<.05$, but no differences between alpha and beta activity was recorded. There was a significant decrease in the ratio of theta/beta, apparently mostly owing to a decrease in theta

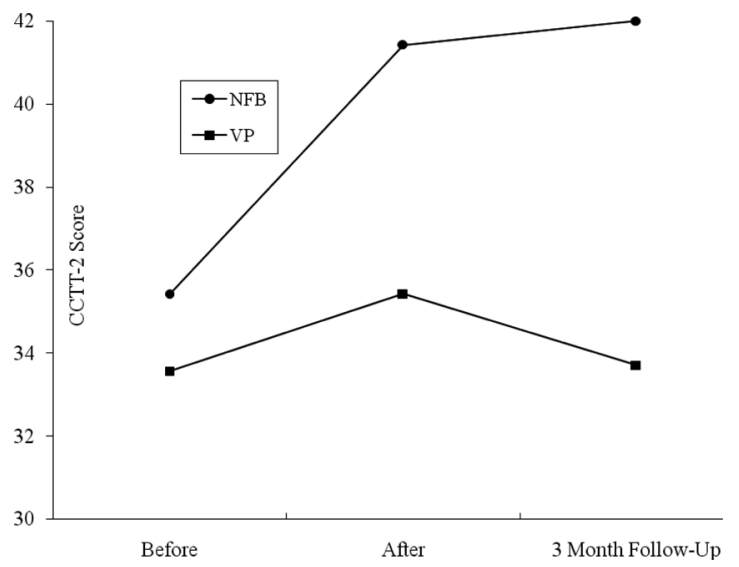

FIGURE 4. Changes of CCTT-2 score in each before, after training, and 3-month follow-up. CCTT-2=Children's Color Trail Test; $\mathrm{NFB}=$ neurofeedback; $\mathrm{VP}=$ visual perception.

activity rather than an increase in beta. At Fp2, a significant decrease in the theta/beta ratio was observed, which seemed to be produced mostly by a decrease in theta activity, but the decrease in theta was not statistically significant, $t(6)=-1.72, p<.10$. Activity levels at Fp2 were low overall compared to Fp1, which seemed to reflect decreased function in the left hemisphere in children with ID (Demos, 2005).

\section{Follow-Up}

The follow-up study assessed whether NFB training effects had been maintained 3 months after training. Scores for the CCTT-2, SCWT, and Digit Span were compared 3 months before and after NFB training. The results are shown in Table 8, and explanations for each test are as follows.

CСTT-2. Figure 4 shows that scores for the NFB group were maintained even 3 months

TABLE 8. Mean and Standard Deviation of Each Test 3 Months Before and After NFB Training

\begin{tabular}{llllllr}
\hline Variable & Group & Before & After & $\begin{array}{l}\text { 3-Month } \\
\text { follow-up }\end{array}$ & Before-follow-up $t$ & After-follow-up $t$ \\
\hline CCTT-2 & NFB $(n=7)$ & $35.43(13.46)$ & $41.43(13.72)$ & $42.20(11.14)$ & $3.74^{* *}$ & 0.00 \\
& VP $(n=7)$ & $33.57(6.32)$ & $35.43(8.36)$ & $33.71(6.92)$ & 0.31 & -1.22 \\
SCWT & NFB $(n=7)$ & $27.00(6.29)$ & $31.29(6.60)$ & $32.57(7.46)$ & $2.74^{* *}$ & 0.84 \\
& VP $(n=7)$ & $29.00(5.09)$ & $31.12(7.47)$ & $29.86(6.38)$ & 0.37 & -0.49 \\
Digit Span & NFB $(n=7)$ & $8.29(3.40)$ & $12.19(3.25)$ & $12.0(3.64)$ & $3.65^{* *}$ & -0.33 \\
& VP $(n=7)$ & $8(3.41)$ & $8.86(7.47)$ & $9.43(4.96)$ & 1.12 & 0.79 \\
\hline
\end{tabular}

Note. CCTT-2 = Children's Color Trail Test-2; SCWT = Stroop Color and Word Test; NFB = neurofeedback; VP= visual perception. ${ }^{*} p<.05 .{ }^{* *} p<.01 .{ }^{* * *} p<.001$, one-tailed test. 


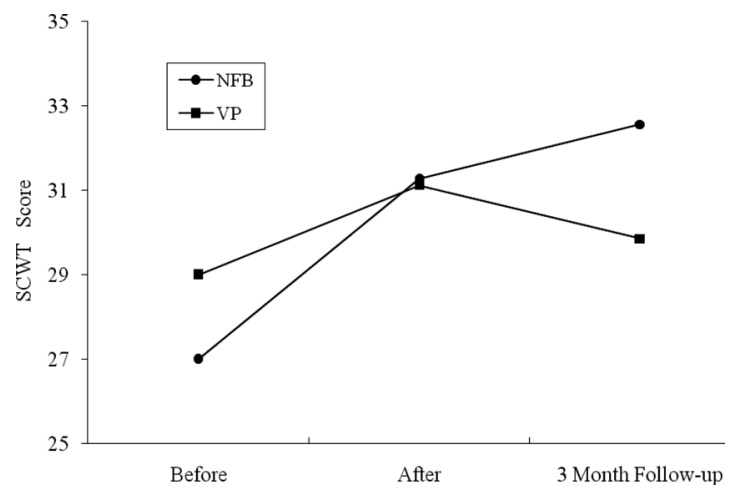

FIGURE 5. Changes of Stroop Color and Word Test (SCWT) score in before, after training, and 3 month follow-up. NFB= neurofeedback; $\mathrm{VP}=$ visual perception.

after training completion, $t(6)=3.74, p<.01$. This finding shows that improved attentional ability resulting from NFB training remained 3 months after training was completed. Scores for the VP group at follow-up were the same as those recorded before the VP training began.

SCWT. Figure 5 shows that SCWT scores of the NFB group were maintained even 3 months after training completion, $t(6)=2.74$, $p<.05$. This result reveals that improved attentional ability resulting from the NFB training remained effective 3 months after training was completed. Scores for the VP group at follow-up decreased slightly compared to those recorded at the end of the VP training.

Digit Span. Figure 6 shows that the Digit Span scores for the NFB group were maintained even 3 months after training completion, $t(6)=3.65, p<.01$. This result shows that

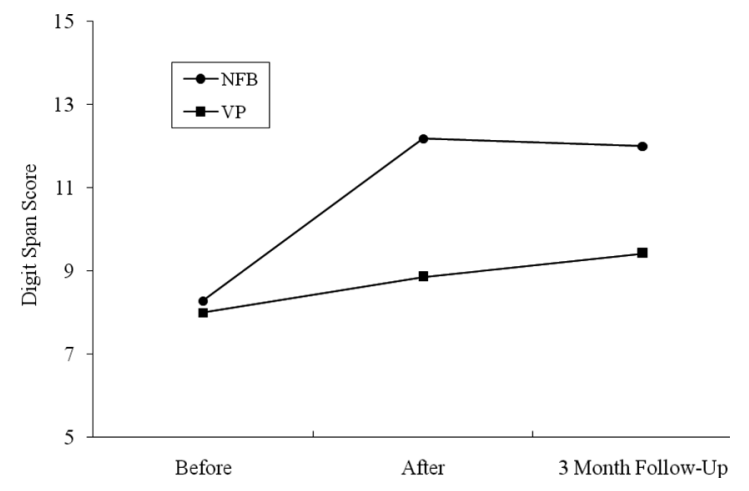

FIGURE 6. Changes of Digit Span score in before, after training, and 3 -month follow-up. NFB = neurofeedback; VP=visual perception. improved attentional ability gained as a result of NFB training remained 3 months after training. Scores for the VP group at follow-up increased slightly compared to those obtained 3 months earlier, but this increase was not significant.

\section{DISCUSSION}

Previous treatment programs for children with ID had limitations in generalizing and maintaining their effects. We challenged these limitations using a neurological perspective positing an association between attention and brain structure, and investigated the effects of a NFB training program in children with ID as an alternative treatment approach. The results and implications of this study are as follows. First, the NFB group showed significantly increased scores on CCTT-2, SCWT, and Digit Span tasks compared to the two control groups. Thus, with this subject sample, the NFB program was more effective than VP or no training in improving attentional ability. These findings could be explained using a theory of brain plasticity, stating that a practical training method targeting brainwave changes could improve the arousal regulation of the brain and consequently influence attentional ability (Kolb \& Gibb, 2011). The NFB group showed improved selective attention, attention span, and automatic reaction inhibition. Attentional ability was improved by beta/SMR uptraining, which improved subjects' brainwave activity and had a direct influence on expanding their memory range and improved their attentional ability.

Second, a follow-up study 3 months after training completion showed that the NFB group maintained their increased scores for attention tasks as measured by the CCTT-2, SCWT, and Digit Span tests. These positive effects of the NFB training program are likely to last more than 3 months. NFB training would be practical in a real school setting because it has long-term effects compared to the effects of traditional methods such as VP training. Surprisingly, the scores obtained on both the CCTT-2 and SCWT continued to increase into the follow-up period. 
Third, reductions in theta and the theta/ beta ratio produced in the right/left frontal lobes for children in the NFB group, suggest that beta/SMR uptraining is effective for attention improvement and can stabilize brain function. Consequently, this study supports the hypothesis that NFB training can help children with ID to learn how to better attend to external stimuli and maintain this ability by themselves.

This study provided a systematic comparison among NFB, VP, and a no-treatment control group, going beyond previous single case studies that have predominated in the research literature on treatments for children with intellectual disabilities. Moreover, NFB assisted the children in this study to produce and stabilize a higher brain arousal state. Consequently, these children with ID could develop self-efficacy in controlling brain activity by themselves.

The limitations of this study and suggestions for future investigations are as follows. First, the NFB training in this study mainly measured brainwave activity in the frontal lobe region. Considering that attentional ability is affected by a variety of regions of the brain, it is necessary to examine and measure several regions of the brain. Second, we are not sure at this point how well the children in our NFB group can apply their improved attentional ability to real life. In general, children with ID show many difficulties in adaptive behaviors just because of their intellectual limitations. Although our study results show that subjects in the NFB group appeared to be significantly improved in attentional ability, all data were obtained from isolated attention tasks, not related to a practical performance in school work and everyday life. Therefore, follow-up studies need to investigate the relationship between NFB training and adaptability in real-life situations.

\section{REFERENCES}

Allinder, R. M. (2000). Effects of teacher selfmonitoring on implementation of curriculum-based measurement and mathematics computation achievement of students with disabilities. Remedial \& Special Education, 21, 219.
American Association on Intellectual and Developmental Disabilities. (2010). Intellectual disability. Washington, DC: Author.

Arns, M., Gunkelman, J., Breteler, M., \& Spronk, D. (2008). EEG phenotypes predict treatment outcome to stimulants in children with ADHD. Journal of Integrative Neuroscience, 7, 421-438.

Arnsten, A. F. T., \& Li, Bao-Ming (2005). Neurobiology of executive functions: Catecholamine influences on prefrontal cortical functions. Biological Psychiatry, 57, 1377-1384.

Bachers, A. (2004). Neurofeedback with cerebral palsy and mental retardation: A case report. Journal of Neurotherapy, 8, 95-96.

Castellanos, F. X. (1997). Toward a pathophysiology of attention-deficit/hyperactivity disorder. Clinical Pediatrics, 36, 381-393.

Corbetta, M., \& Shulman, G. L. (2002). Control of goal-directed and stimulus-driven attention in the brain. Nature Reviews Neuroscience, 3, 201-215.

Deci, E. L. (2004). Promoting intrinsic motivation and self-determination in people with mental retardation. International Review of Research in Mental Retardation, 28, 1-29.

Demos, J. N. (2005). Getting started with neurofeedback. New York, NY: Norton.

Duncan, J., \& Owen, A. M. (2000). Common regions of the human frontal lobe recruited by diverse cognitive demands. Trends in Neuroscience, 23, 475-483.

Egner, T., \& Gruzelier, J. (2001). Learned self-regulation of EEG frequency components affects attention and event-related brain potentials in human. Neuroreport, 12, 4155-4259.

Eysenck, M. W., \& Keane, M. T. (2005). Cognitive psychology: A student's handbook (5th ed.). New York, NY: Psychology Press.

Fernandez, T., Harmony, T., FernandezBouzas, A., Diaz-Comas, L., Prado-Alcala, R. A., ... Garcia-Martinez, F. (2007). Change in EEG current sources induced by neurofeedback in learning disabled children. Applied Psychophysiology \& Biofeedback, 32, 169-183.

Filipek, P. A. (1999). Neuroimaging in the developmental disorder: The state of the 
science. Journal of Child Psychology and Psychiatry, 40, 113-128.

Fleischman, M. J., \& Othmer, S. (2005). Case study: Improvements in IQ score and maintenance of gains following EEG biofeedback with mildly developmentally delayed twins. Journal of Neurotherapy, 9(4), 35-46.

Fox, R., \& Oross, S. III (1992). Perceptual deficits in mildly mentally retarded adults. In N. W. Bray (Ed.), International review of research in mental retardation (pp. 1-27). New York, NY: Academic Press.

Frostig, M., \& Horne, D. (1964). The Frostig program for the development of visual perception teacher's guide. Chicago, IL: Follett Educational Corporation.

Gracenin, C. T., \& Cook, J. E. (1997). Alpha biofeedback and LD children. Academic Therapy, 12, 275-279.

Hernandez, M. T., Sauerwein, H. C., Jambaqué, I., De Guise, E., Lussier, F., Lortie, A., ... Lassonde, M. (2002). Deficits in executive functions and motor coordination in children with frontal lobe epilepsy. Neuropsychologia, 40, 384-400.

Hoza, B., \& Pelham, W. E. (1993). Handbook of predescriptive treatments for children and adolescents. Boston, MA: Allyn \& Bacon.

Jackson, S., Marroccos, R., \& Posner, M. (1994). Networks of anatomical areas controlling visuospatial attention. Neural Networks, 7, 925-944.

Kim, Y. J. (2000). Development of a brain-cycle learning model based on the electroencephalographic analysis of learning activities and application to science learning (Unpublished doctoral dissertation). Seoul National University, Republic of Korea.

Kirk, S. A., \& Gallagher, J. J. (1983). Educating exceptional children. Boston, MA: Houghton Mifflin.

Kolb, B., \& Gibb, R. (2011). Brain plasticity and behaviour in the developing brain. Journal of the Canadian Academy of Child \& Adolescent Psychiatry, 20, 265-276.

Kwak, G. J., Park, H. W., \& Park, K. B. (2001). Manual of K-WISC-III. Seoul, Korea: Specialized Education.
LaBerge, D. (1995). Computational and anatomical models of selective attention in object identification. In M. Gazzanoga (Ed.), The cognitive neuroscience (pp. 649-663). Cambridge, MA: MIT Press.

Lavie, N. (2005). Distracted and confused? Selective attention under load. Trends in Cognitive Science, 9, 75-82.

Linden, M., Habib, T., \& Radojevic, V. (1996). A controlled study of the effects of EEG biofeedback on the cognition and behavior of children with attention deficit disorder and learning disabilities. Biofeedback and Self-Regulation, 21(1), 35-49.

Llorente, A. M., Williams, J., Satz, P., \& D'Elia, L. (2003). Children's color trails test $1 \& 2$ manual. Lutz, FL: Psychological Assessment Resources.

Lubar, J. F. (1985). EEG biofeedback and learning disabilities. Theory into practice. Learning and the Brain, 24, 106-111.

Lubar, J. F. (1991). Discourse on the development of EEG diagnostics and biofeedback for attention-deficit/ hyperactivity disorders. Biofeedback and Self-Regulation, 16, 201-225.

Lubar, J. F. (1995). Neurofeedback for the management of attention-deficit/hyperactivity disorders. In M. S. Schwartz (Ed.), Biofeedback: A practitioner's guide (pp. 409-437). New York, NY: Guilford.

Lubar, J. F., Swartwood, M. O., Swartwood, J. N., \& Timmermann, D. L. (1995). Quantitative EEG and auditory event-related potentials in the evaluation of attention-deficit disorder: Effects of methylphenidate and implications for neurofeedback training. Journal of Psychoeducational Assessment Monographs, 143-160.

Lubar, J. O., \& Lubar, J. F. (1984). Electroencephalographic biofeedback of SMR and Beta for treatment of attention deficit disorder in a clinical setting. Biofeedback and SelfRegulation, 9, 1-23.

Luria, A. R. (1973). The working brain: An introduction to neuropsychology. New York, NY: Basic Books.

Mesulam, M. M. (1981). A cortical network for directed attention and unilateral neglect. Annals of Neurology, 10, 309-325. 
Monastra, V. J., Lubar, J. F., \& Linden, M. (2001). The development of a quantitative electroencephalographic scanning process for attention deficit-hyperactivity disorder: Reliability and validity studies. Neuropsychology, 15, 136-144.

Muñoz-Ruata, J., Caro-Martínez, E., Pérez, L. M., \& Borja, M. (2010). Visual perception and frontal lobe in intellectual disabilities: A study with evoked potentials and neuropsychology. Journal of Intellectual Disability Research, 54, 1116-1129.

Othmer, S., Othmer, F. S., \& Marks, S. C. (1991). EEG biofeedback training for attention deficit disorder: Specific learning disabilities, and associated conduct problem. New York, NY: Oxford University Press.

Posner, M. I. (1980). Orienting of attention. Quarterly Journal of Experimental Psychology, 32, 3-25.

Posner, M. I., \& Peterson, S. (1990). The attention system of the human brain. Annual Review of Neuroscience, 13, 25-42.

Posner, M., \& Raichle, M. (1994). Networks of attention. Images of mind. New York, NY: Scientific American Library.

Rezaiyan, A., Mohammadi, E., \& Fallah, P. A. (2007). Effect of computer game intervention on the attention capacity of mentally retarded children. International Journal of Nursing Practice, 13, 284-288.

Rizzo, A., \& Buckwalter, J. G. (1997). Virtual reality and cognitive assessment and rehabilitation: The state of the art. In G. Riva (Ed.), Virtual reality in neuro-psycho-physiology: Cognitive, clinical, and methodological issues in assessment and rehabilitation (pp. 123-146). Amsterdam, the Netherlands: IOS Press.

Rossiter, T. (2002). Neurofeedback for AD/ HD: A ratio feedback case study and tutorial. Journal of Neurotherapy, 6(3), 9-35.

Shin, M. S. \& Goo, H. J. (2007). A manual of Stroop color and word test for children. Seoul, Korea: Hakjisa.

Shin, M. S., \& Park, M. J. (2007). A manual of children's color trails test. Seoul, Korea: Hakjisa.
Shouse, M. N., \& Lubar, J. F. (1979). Operant conditioning of EEG rhythms and Ritalin in the treatment of hyperkinesis. Biofeedback and Self Regulation, 4, 301-312.

Stogdill, R. M. (1938). Some behavior adjustment techniques in use with mentally retarded children. Journal of Exceptional Children, 5(2), 25-45.

Switzky, H. N. (2001). Personality and motivational self-system process in people with mental retardation: Old memories and new perspectives. In H. N. Switzky (Ed.), Personality and motivational difference in persons with mental retardation (pp. 343-378). Mahwah, NJ: Erlbaum.

Tansey, M. A. (1991). Wechsler (WISC-R) changes following treatment of learning disabilities via EEG biofeedback training owing a private practice setting. Australia Journal of Psychology, 43, 147-153.

Thorell, L. B., \& Rydell, A. M. (2008). Behavior problems and social competence deficits associated with symptoms of attentiondeficit/hyperactivity disorder: Effects of age and gender. Child: Care, Health and Development, 34, 584-595.

Tomporowski, P. D., \& Ellis, N. R. (1984). Effects of exercise on the physical fitness, intelligence, and adaptive behavior of institutionalized mentally retarded adults. Applied Research in Mental Retardation, 5, 329-337.

Uyanik, M., Bumin, G., Kayihan, H., \& Bumin, G. (2003). Comparison of different therapy approaches in children with down syndrome. Pediatrics International, 45(1), 68-73.

Wechsler, D. (1974). Manual for the Wechsler Intelligence Scale for Children-Revised. New York, NY: Psychological Corporation.

Welsh, M. C., Pennington, B. F., \& Grosser, D. B. (1991). A normative-developmental study of executive function: A window on prefrontal function in children. Developmental Neuropsychology, 7, 131-149.

Yeo, K. E. (1987). Theory and practice in visual perception training program. Daegu, Korea: Daegu University Press. 


\section{APPENDIX}

TABLE A1. Analysis of Variance Data: Group (3) $\times$ Time (2)

\begin{tabular}{|c|c|c|c|c|c|c|}
\hline Test & Source & & SS & $d f$ & $M S$ & $F$ \\
\hline \multirow[t]{5}{*}{ ССТT-2 } & & Time (A) & 61.92 & 1 & 91.52 & $12.08^{*}$ \\
\hline & Within subjects & $\mathrm{A} \times \mathrm{C}$ & 22.42 & 2 & 25.02 & $3.30^{* *}$ \\
\hline & & Error & 57.14 & 18 & 7.58 & \\
\hline & Between subjects & Group (C) & 288.14 & 2 & 144.07 & .67 \\
\hline & & Error & 3859.85 & 18 & 214.43 & \\
\hline \multirow[t]{5}{*}{ SCWT } & & Time (A) & 91.52 & 1 & 61.93 & $19.50^{* *}$ \\
\hline & Within subjects & $A \times C$ & 50.04 & 2 & 11.21 & $3.53^{*}$ \\
\hline & & Error & 136.42 & 18 & 3.18 & \\
\hline & Between subjects & Group (C) & 13.86 & 2 & 6.93 & .103 \\
\hline & & Error & 1210.29 & 18 & 67.24 & \\
\hline \multirow[t]{5}{*}{ Digit Span } & & Time $(\mathrm{A})$ & 38.06 & 1 & $3 S .06$ & $20.25^{* *}$ \\
\hline & Within subjects & $A \times C$ & 23.05 & 2 & 11.52 & $6.13^{*}$ \\
\hline & & Error & 33.86 & 18 & 1.88 & \\
\hline & Between subjects & Group (C) & 34.86 & 2 & 17.43 & .92 \\
\hline & & Error & 342.14 & 18 & 19.00 & \\
\hline
\end{tabular}

Note: $\mathrm{CCTT}-2=$ children's color and trail test $-2 ; \mathrm{SCWT}=$ stroop color and word test.

${ }^{*} p<.05,{ }^{* *} p<.01,{ }^{* * *} p<.001$ (for one-tailed test). 